August -2004

\title{
Blended Learning and Sense of Community: A comparative analysis with traditional and fully online graduate courses
}

\author{
Alfred P. Rovai and Hope M. Jordan \\ Regent University \\ USA
}

\begin{abstract}
Blended learning is a hybrid of classroom and online learning that includes some of the conveniences of online courses without the complete loss of face-to-face contact. The present study used a causal-comparative design to examine the relationship of sense of community between traditional classroom, blended, and fully online higher education learning environments. Evidence is provided to suggest that blended courses produce a stronger sense of community among students than either traditional or fully online courses.
\end{abstract}

Keywords: Blended learning; sense of community; higher education; online learning; computermediated communication; faculty training

\section{Introduction}

Times are changing for higher education. From the de-emphasis on thinking about delivering instruction and the concurrent emphasis placed on producing learning, to using technology to expand distance education, to the recognition of the importance of sense of community, we are witnessing a transformation of higher education. A decade ago, Davis and Botkin (1994) wrote:

$[w]$ ith the move from an agrarian to an industrial economy, the small rural schoolhouse was supplanted by the big brick schoolhouse. Four decades ago we began to move to another economy but we have yet to develop a new educational paradigm, let alone create the 'schoolhouse' of the future, which may be neither school nor house (p. 23).

Today, we appear to be well along the road of creating that new schoolhouse and, as Davis and Botkin predicted, it is not constructed exclusively of bricks and mortar.

\section{Producing Learning}

Barr and Tagg (1995) described the first focus of change as a paradigm shift in which universities were re-inventing their purpose and thinking less about delivering instruction and more about 
producing learning in student-centered environments. According to Barr and Tagg, universities are moving away from a faculty-centered and lecture-based paradigm to a model where learners are the focus, where faculty members become learning environment designers, and where students are taught critical thinking skills. Thus, the role of professors in the new schoolhouse is to serve their students by ensuring student learning is of paramount importance. They support their students by attending to their intellectual growth and self-autonomy, and by instilling in them an awareness of important social issues, thus supporting their ability to become more productive members of society as lifelong learners working toward the common good.

Gardiner $(1994,1998)$ endorsed the need for classroom change to allow students to acquire more significant kinds of cognitive learning, particularly critical thinking skills. He pointed out that research shows the ability of university students to reason with abstractions is strikingly limited. He argued that many university students have not yet reached the formal operational level of cognitive development. Consequently, revisions to curricula, instructional and advising practices, and campus climates are needed to improve student learning and to promote student growth. If we envision a university education as education in the conduct and strategy of inquiry itself, then the university becomes society's unique site where students learn how to think, learn, produce, and evaluate knowledge, providing the basis for lifelong, independent learning (Rury, 1996).

An important implication of this shift is the need for a recommitment to creating an ideal learning environment for students and employing new pedagogies and technologies, where appropriate. In implementing change, one reality seems clear. Universities will face more competition to attract quality-conscious students and thus cannot afford to underestimate the depth and speed of the changes required to remain competitive. Change is not easy, however, and there is considerable pressure from within the university to preserve the status quo, particularly from faculty members. In many cases, professors teach as they were taught and resist change (Gardiner, 1998), often using academic freedom as an academic crutch. Since faculty promotion and tenure, at present, are largely based on research and publication, some professors zealously feel that they should not take away from their research or writing time to change curricula and pedagogy, for the potential rewards are not worth the time or risk to them. Consequently, many professors still use the traditional lecture as their instructional strategy of choice.

Several learning theories are particularly relevant to the learning-centered university classroom. Approaches to learning that promote social constructivism, or learning within a social context, and that feature active group construction of knowledge, rather than transfer of knowledge, provide ideal learning environments for the new schoolhouse. These approaches to learning are highly consistent with the views of Barr and Tagg (1995), who wrote that the new educational paradigm "creates environments...that bring students to discover and construct knowledge for themselves" (p. 15).

\section{Distance Education}

A second focus of change is the shift from providing exclusively traditional classroom instruction to reaching out to students by delivering courses at a distance using technology. Distance education is already a pervasive element of higher education and it continues to rapidly expand. Research, however, suggests that online courses are not suitable for all types of students and faculty. Collins (1999) noted that students and teachers react to new educational technologies with varied emotions, ranging from enthusiasm to disabling fear. Abrahamson (1998) reported that distance education required students who were self-regulated and independent. Marino 
(2000) also discovered that some students experienced difficulty adjusting to the structure of online courses, managing their time in such environments, and maintaining self-motivation.

The text-based computer-mediated communication (CMC) that is used by Internet-based elearning systems for discussion board and email discourse is a powerful tool for group communication and cooperative learning that promotes a level of reflective interaction that is often lacking in a face-to-face, teacher-centered classroom. However, the reduced non-verbal social cues in $\mathrm{CMC}$, such as the absence of facial expressions and voice inflections, can generate misunderstandings that adversely affect learning.

Sikora and Carroll (2002) reported that online higher education students tend to be less satisfied with totally online courses when compared to traditional courses. Fully online courses also experienced higher attrition rates (Carr, 2000). The research is mixed regarding the reasons for these higher attrition rates, however. Hara and Kling (2001), conducting a study of online courses, found that feelings of isolation were an important stress factor for online students, but not the primary factor as frequently mentioned in the professional literature. Rather, "[s]tudents reported confusion, anxiety, and frustration due to the perceived lack of prompt or clear feedback from the instructor, and from ambiguous instructions on the course website and in e-mail messages from the instructor" (p. 68). Thus, it may be that the reason some online courses suffer more dropouts is less related to the course delivery medium and more related to the online course design and pedagogy employed by some online faculty who have limited skills in using $\mathrm{CMC}$ to facilitate learning and to nurture sense of community.

\section{Sense of Community}

The third major focus of change in higher education is the increased attention given to the importance of a strong sense of community. McMillan and Chavis (1986) offered the following definition of sense of community, "a feeling that members have of belonging, a feeling that members matter to one another and to the group, and a shared faith that members' needs will be met through their commitment to be together" (p. 9). Sergiovanni (1994) stressed the need for authentic community in schools, a tie binding learners and teachers through shared values, ideals, and goals.

Research evidence suggests that low sense of community is related to two student characteristics associated with attrition: student burnout (McCarthy, Pretty, and Catano, 1990) and feelings of isolation (Haythornthwaite, Kazmer, Robins, and Shoemaker, 2000; Morgan and Tam, 1999). Tinto (1975) argued that insufficient interactions of higher education students with peers and faculty and differences with the prevailing value patterns of other students, are also likely to result in dropouts. In other words, students who feel they do not fit in and have low sense of community tend to feel isolated and are at-risk of becoming dropouts.

\section{Blended Learning}

Blended learning is an important building block of the new schoolhouse that offers students both flexibility and convenience, important characteristics for working adults who decide to pursue postsecondary degrees. According to Colis and Moonen (2001), blended learning is a hybrid of traditional face-to-face and online learning so that instruction occurs both in the classroom and online, and where the online component becomes a natural extension of traditional classroom learning. Blended learning is thus a flexible approach to course design that supports the blending 
of different times and places for learning, offering some of the conveniences of fully online courses without the complete loss of face-to-face contact. The result is potentially a more robust educational experience than either traditional or fully online learning can offer.

From a course design perspective, a blended course can lie anywhere between the continuum anchored at opposite ends by fully face-to-face and fully online learning environments. The faceto-face component can be either on the main university campus or the professor can travel to a remote site in order to meet with students. Martyn (2003) described a successful blended learning model. It consists of an initial face-to-face meeting, weekly online assessments and synchronous chat, asynchronous discussions, e-mail, and a final face-to-face meeting with a proctored final examination.

Dziuban and Moskal (2001) reported that blended courses at the University of Central Florida replaced face-to-face class time with online learning so that a three-hour course occupied only one hour of actual face-to-face classroom time. Such courses allowed the weekly operation of multiple classes in a classroom previously occupied by only one course, thus making more efficient use of existing university infrastructure. Moreover, they reported that blended courses, when compared to traditional courses, had equivalent or reduced student withdrawal rates as well as equivalent or superior student success rates.

Voos (2003) suggested that it is unlikely that the blendedness (sic) makes the difference in such courses, but rather the fundamental reconsideration of course design in light of new instructional and media choices and the learning strengths and limitations of each. Joyce Neff (1998), a professor of writing, found that teaching a blended course had profound effects on her teaching. She wrote: "[t]he ways I perceived and manipulated the medium, the ways I imagined the subjectivities of my students, and the ways intermediaries affected my authorities all influenced my writing pedagogy" (p. 154). Privateer (1999) summarized the direction needed with the following passage:

Opportunities for real change lie in creating new types of professors, new uses of instructional technology and new kinds of institutions whose continual intellectual self-capitalization continually assures their status as learning organizations (p. 72).

\section{Purpose}

Prior research has not examined sense of community in higher education blended learning environments. Consequently, the purpose of the present study was to examine how sense of community differed across fully traditional, blended, and fully online courses. The research hypothesis was that sense of community would be strongest in the blended course. The rationale was that a combination of face-to-face and online learning environments provides a greater range of opportunities for students to interact with each other and with their professor. These interactions should result in increased socialization, a stronger sense of being connected to each other, and increased construction of knowledge through discourse, thus providing stronger feelings that educational goals were being satisfied by community membership. 


\section{Methodology}

\section{Participants}

Study participants consisted of 68 graduate students enrolled in three graduate-level education courses during the same semester. All participants were employed as full-time K-12 teachers seeking a Master's degree in education. The overall volunteer rate was 86 percent. By course, the total number of students enrolled, the number of students who volunteered, and the volunteer rates were as follows: a) traditional course, 26 enrolled, 24 volunteered, 92.31 percent volunteer rate; b) blended course, 28 enrolled, 23 volunteered, 82.14 percent volunteer rate; and c) fully online course, 25 enrolled, 21 volunteered, 84.00 percent volunteer rate.

\section{Setting}

All three courses were presented by a small accredited university located in an urban area of southeastern Virginia. These courses were selected for inclusion in this study because they were each taught by full-time professors of education with reputations for being superb teachers universally well regarded by their students and who valued interaction and collaborative group work. The professors were also noted for possessing such personal qualities as sociability, sensitivity, discernment, concern, and high expectations regarding student achievement.

The traditional course presented instruction on educational collaboration and consultation, and met Wednesday evenings throughout the semester in a classroom on the main university campus. Students resided in the same geographical area. Each class meeting lasted approximately three hours for total face-to-face time of approximately 48 hours. Online technologies were not used in this course. The professor employed a mix of textbook study assignments, lecture with class-wide discussions, some collaborative group work, and authentic assessment tasks requiring individual work. The group work involved two to three students working collaboratively on a single project assigned by the instructor.

The blended course covered legal and ethical aspects associated with teaching disabled students and consisted of both face-to-face and asynchronous online components. Like the traditional course, students resided in the same geographical area. Assignments emphasized practical application, authentic tasks, collaborative action research, and group projects, all complemented with textbook readings. The course started with an initial face-to-face session followed by two Friday evening and Saturday sessions, spread evenly throughout the 16-week semester, for a total of approximately 14 face-to-face hours. These sessions were conducted either on the main campus or at remote sites, chosen based on their accessibility to students and included activities such as guest speakers, group project presentations, group simulations, interactive videos, and discussions. The online component was delivered using the BlackboardSM e-learning system, which allowed for presentation of online content and the extensive use of student-student and student-professor asynchronous dialogue as extensions of the face-to-face sessions.

The fully online course covered curriculum and instructional design and was delivered entirely online using the BlackboardSM e-learning system. Unlike the other two courses, students were geographically dispersed throughout the U.S. The online professor used a mix of textbook study assignments, collaborative online discussion topics using group discussion boards consisting of 12 to15 students each, and authentic assessment tasks requiring individual work. The only collaborative group work in the course was the weekly problem-oriented discussion topics posted 
by the instructor. These topics required students to interact with each other as they moved toward achieving consensus on solutions to the issues raised by the instructor. In order to encourage participation in the discussion boards, active and constructive online interactions accounted for 10 percent of the course grade.

\section{Instrumentation}

The Classroom Community Scale (CCS) was used to measure connectedness and learning (Rovai, 2002). This instrument consisted of 20 self-report items, such as . feel isolated in this course and . feel that this course is like a family. Following each item was a five-point Likert scale of potential responses: strongly agree, agree, neutral, disagree, and strongly disagree. The participants check the place on the scale that best reflects their feelings about the item. Scores are computed by adding points assigned to each of the 20 five-point items, with 10 items allocated to each subscale. These items are reverse-scored where appropriate to ensure the least favorable choice is always assigned a value of 0 and the most favorable choice is assigned a value of 4 . The connectedness subscale represented the feelings of students regarding their cohesion, community spirit, trust, and interdependence. The learning subscale represented the feelings of community members regarding the degree to which they shared educational goals and experienced educational benefits by interacting with other members of the course. Scores on each subscale can range from 0 to 40 , with higher scores reflecting a stronger sense of classroom community.

The results of a factor analysis confirmed that the two subscales of connectedness and learning were latent dimensions of the classroom community construct (Rovai, 2002). Cronbach's coefficient alpha for the full classroom community scale was .93. Additionally, the internal consistency estimates for the connectedness and learning subscales were .92 and .87, respectively. In the present study, Cronbach's coefficient alpha for the full classroom community scale and the connectedness and learning subscales were $.92, .90$, and .84 , respectively.

End-of-course student evaluations were also used to obtain anecdotal data regarding student perceptions of their respective courses. These evaluations are voluntary on the part of each student and are submitted anonymously directly to the university. Instructors receive written copies of comments disaggregated by course after course grades are submitted to the university registrar.

\section{Procedures}

The CCS was completed by the traditional and blended course participants during face-to-face meetings proctored by the course's professor while fully online course participants completed the CCS via an online survey. All participants completed the pretest during the second week of the semester and the posttest during the final two weeks of the semester. Participants were unaware of their final course grades when they completed the CCS.

\section{Design and Data Analysis}

A causal-comparative design was used to determine whether the mean differences in sense of community measured at the end of traditional, blended, and fully online graduate courses, as reflected by the composite dependent variable of the two CCS subscales of connectedness and learning, were larger than expected by chance after adjusting for preexisting differences in the two subscales. A multivariate analysis of covariance (MANCOVA) was used to analyze the data 
in order to provide statistical matching of groups based on the pretest results, since random assignment of participants to groups was not possible in this study. Effect size was calculated using the eta squared (h2) statistic and interpretation was based on Cohen's (1977) thresholds of .01 for a small effect, .06 for a moderate effect, and .14 for a large effect. Assumptions tested and specific statistical procedures used in the analyses are described in the following results section.

\section{Results}

A total of 51 ( 75.0 percent) of the students were females and 17 (25.0 percent) were males. Overall, 13 students (19.1 percent) reported their age as being 25 years old or less, 16 (23.5 percent) were between 26 and 30, 18 (26.5 percent) were between 31 and 40, 18 (26.5 percent) were between 41 and 50, and 3 (4.4 percent) were over 50 years old. For ethnicity, 53 (77.9 percent) reported being white, 10 (14.7 percent) were African-American, 2 (2.9 percent) were Hispanic, and 3 (4.4 percent) were bi-racial. Chi-square contingency table analysis provided evidence that there were no significant differences in the composition of the three courses by gender, age, or ethnicity. The pooled pretest means (with standard deviations in parentheses) for the connectedness and learning subscales were 28.75 (4.90) and 32.53 (3.66), respectively, while the pooled posttest statistics were 31.57 (6.18) and 34.44 (4.67), respectively. The means and standard deviations for the two subscales by course are displayed in Table 1.

Tahle 1. Descriptive Statistics

\begin{tabular}{|c|c|c|c|c|}
\hline \multirow[b]{2}{*}{ Variable } & \multicolumn{2}{|c|}{ Pretest scores } & \multicolumn{2}{|c|}{ Posttest scores } \\
\hline & $M$ & $S D$ & $M$ & $S D$ \\
\hline \multicolumn{5}{|c|}{ Traditional course $(n=24)$} \\
\hline Comuectedress & 32.63 & 4.12 & 32.50 & 4.85 \\
\hline Leaming & 34.38 & 2.39 & 35.88 & 3.55 \\
\hline \multicolumn{5}{|c|}{ Blended course $(n=23)$} \\
\hline Coruriectedruss & 26.70 & 4.10 & 32.70 & 4.42 \\
\hline Leaming & 30.57 & 2.76 & 34.26 & 3.74 \\
\hline \multicolumn{5}{|c|}{ Fully orbine course $(n=21)$} \\
\hline Cormectedress & 26.57 & 3.83 & 29.29 & 8.45 \\
\hline Learning & 32.57 & 4.61 & 3300 & 6.20 \\
\hline
\end{tabular}

$M$ te: $N=68$. Scores car range from 0 to 40 for each variable, with higher scores reflectirg a stronger serse of classroom comurumity.

A one-way MANCOVA was conducted on two dependent variables: posttest connectedness and posttest learning. The independent variable was type of course (traditional, online, and blended). 
The two covariates were pretest connectedness and pretest learning. Data screening revealed no univariate or multivariate within-cell outliers at $p<.001$. Results of evaluation of normality, linearity, singularity, and multicollinearity were satisfactory. Table 2 displays all Personian bivariate correlations for the dependent variables and covariates. The homogeneity of slopes assumption was tested by examining two interaction effects for each dependent variable: type of course $\mathrm{x}$ pretest connectedness and type of course $\mathrm{x}$ pretest learning. The assumption was tenable although the partial $\eta 2=.11$ for the type of course $x$ pretest connectedness interaction associated with posttest connectedness was of medium size, a cause for some concern. The assumption of homogeneity of variance-covariance matrices was not met, Box's $M=16.06, F(6,96620.57)=$ $2.56, p=.02$. Consequently, Pillai's criterion, instead of Wilks' lambda, was used to evaluate multivariate significance because of its robustness to moderate violations of this assumption.

Table 2. Inter-correlations

\begin{tabular}{lcccc}
\hline Variable & 1 & 2 & 3 & 4 \\
\hline 1. Fretest cornectedness & 1.00 & .25 & .57 & .41 \\
2. Fosttest connectedness & & 1.00 & .57 & .85 \\
3. Pretest learring & & & 1.00 & .67 \\
4. Fosttest learring & & & & 1.00 \\
\end{tabular}

Mote: $p=0$

The MANOVA revealed that the combined dependent variables were significantly affected by course type, Pillai's trace $=.23, F(4,126)=4.09, p=.004$, partial $\eta 2=.12$. Tests of betweensubjects effects were also conducted to investigate the impact of type of course on individual dependent variables. Both connectedness, $F(1,63)=9.37, M S E=20.70, p<.001$, partial $\eta 2=$ .23 , and learning, $F(1,63)=4.74, M S E=11.06, p=.01$, partial $\eta 2=.13$, differed significantly.

The blended course possessed the highest estimated marginal mean (i.e., the adjusted posttest mean) of the connectedness variable $(M=34.91)$, followed by the traditional course $(M=30.78)$ and the online course $(M=28.83)$. Based on these estimated marginal means and the results of Sidak's $t$ test, which adjusts the observed significance level for the fact that multiple comparisons are made, participants in the blended course scored significantly higher on the connectedness posttest, after adjustment based on pretest results, than either participants in the traditional course, $p=.04$, or the online course, $p<.001$. The difference between participants in the traditional course and the online course was not significant. The blended course also possessed the highest estimated marginal mean for learning $(M=36.17)$, followed by the traditional course $(M=34.03)$ and the online course $(M=33.01)$. Based on Sidak's $t$ test, the participants in the blended course scored significantly higher on learning than those in the online course, $p=.01$, after adjustment based on pretest results. The differences for other pairwise comparisons were not significant. 


\section{Discussion}

The present study examined the relationship of sense of community between traditional classroom, blended, and fully online higher education learning environments. After adjusting for course pretest differences, the combined dependent variable of connectedness and learning differed significantly among the three courses. The effect size, as measured by partial $\eta 2$, was medium. The blended course possessed a significantly higher adjusted mean connectedness score than either the traditional or online courses with a large effect size. The blended course also possessed a significantly higher adjusted mean learning score than the online course, but with a medium effect size.

An examination of the variability of connectedness and learning scores by course, as reflected by their standard deviations as well as by the significant differences found in their variancecovariance matrices, showed that the scores of online course students were substantially more diverse than either the two other courses. Moreover, the distribution of these two community variables among online students revealed a decidedly negative skew. These results suggest the existence of one or more confounding variables. Such variables are likely to be related to student characteristics, such as learning style preference, that facilitate the development of strong feelings of community in some online students, while other students remain at a psychological distance from their peers in the same learning environment.

Often cited characteristics of successful online students include interest in the material taught, self-motivation, independent and self-directed learner, critical thinker, family support, positive and timely feedback, accepts responsibility for own learning, organized, and practical knowledge in the use of computers (Irizarry, 2002). Student deficiencies in any of these factors could possibly result in a weak sense of community and explain the relatively large variability and negative skew of sense of community variables among students in the online course. Since students in the blended course exhibited similar sense of community and variability as students in the traditional course, offering the convenience of fully online courses without the complete loss of face-to-face contact may be adequate to nurture a strong sense of community in students who would feel isolated in a fully online course.

The ability of the blended course to generate stronger feelings of community than the fully online course was expected, based on the frequent online student complaint of feeling isolated (e.g., Haythornthwaite et al., 2000; Morgan and Tam, 1999). Additionally, the frustrations some students feel in fully online courses, particularly those who are dependent learners, are less selfregulated, and need frequent direction and reinforcement from a visible professor, are eased when combined with periodic opportunities for face-to-face interactions. Fully online learning environments also require technological ability and frequency of usage that varies from student to student based on individual characteristics. Accordingly, all these differences influence the benefits that each student derives from online environments and help explain why some students are not fully satisfied with online courses and feel isolated. Likewise, discussions in traditional classrooms, where vocal students can dominate and discussions may be superficial, spontaneous, and limited, can frustrate those students with a more introverted personality and thus help explain why sense of community in the blended course was stronger than in the traditional course.

All student comments regarding the blended course were positive. Many initially expressed concern regarding the online component of the class at the initial face-to-face session. They were not sure that they could handle the technological aspects and the required independent learning. They were also uncertain how they would feel about communicating with other students and the 
professor online. Nonetheless, students predominantly ended up expressing the benefits of the online portion of their classes. As one student explained in the anonymous end-of course student evaluations of the course, "As a teacher, I would never have made it through this semester without the practical guidance of this course along with the freedom of the online component." Another student wrote: "I feel the experiences this program has given me have better prepared me for the classroom than any lecture I had in my traditional undergraduate work, and I've been teaching for six years."

Students felt that the authentic nature of the assignments tied nicely with what they were doing in their own classrooms everyday as practicing K-12 teachers. One student wrote, "this course was rigorous, yet extremely workable for teaching professionals because the assignments directly impacted my teaching practices during the year." Several blended students also commented that they would not have been able to complete the course without the online component, as they needed to continue working while attending school. They also pointed out, however, that the face-to-face weekend classes were a valuable component both academically and in building professional relationships and a strong sense of community. Students often left class on Saturday and tried a new technique, such as implementing a new behavior management plan or using a new academic strategy, the very next week. Having strategies modeled in class, participating in simulations and group work, as well as face-to-face feedback from peers and instructors, were all considered important to the overall learning experience. Although such behavior may have occurred in the other two courses, students did not mention it in their end-of-course evaluations.

Students provided a mix of negative and positive comments about the fully online course. Negative comments addressed the limitations of the text-based nature of CMC. A typical negative comment was:

Trying to understand abstract concepts from only printed words in the discussion forums was and is still difficult for me. I have to be able to visualize within a context. I need a more visual approach. I need the professor to draw pictures and diagrams or show slides as he speaks.

Additionally, there were some student-professor misunderstandings, possibly due to the reduced social cues in text-based discussions. One student wrote to the professor: "Some of your responses to other students appeared sharp and frank. So instead of calling you, I just depended on my own wit and received help from my colleagues." The professor's view was that his communicator style was direct, concise, and to the point in order to minimize misunderstandings and manage time in responding to numerous messages each day. There was no evidence of such misunderstandings in the blended or traditional courses, suggesting that the opportunity for faceto-face discussions allowed everyone to become acquainted with each other, which may have assisted in the interpretation of subsequent text-based communication in the online course.

Positive comments regarding the fully online course centered on the value of reflective thinking and the extra time to process information. "I noticed that I process the information better when it is presented online, because I have to analyze it myself before I hear someone else's interpretation of what I am learning," was one online student's comment. The extra time to process information allowed students to give more in-depth answers and promoted critical thinking skills. However, the professor's skills in facilitating online discussions are essential to the success of the course. A comment written by one student underscores this point: 
[The professor] corrected gaps in understanding immediately when they occurred on Blackboard. This was of great benefit, especially to those individuals who spent large amounts of time on Blackboard. We were able to discuss at length with him any misconceptions or errors in lingo. The level of difficulty of this course is such that the instructor must be vigilant, pointed, and on top of the learners each step of the way, if concepts are to be purely assimilated and applied. I feel that face-to-face is ideal for teaching a course as this, but if (and ONLY if) an instructor can master the online format, as our professor has, is it doable as an online course.

Course quality can vary due to a number of factors including available technology and the capabilities of professors who design and teach the courses. While technology has the great potential to enhance student's active learning, the use of technology requires a compatible pedagogy to achieve its benefits. Consequently, within each type of course, sense of community among students is likely to co-vary based on the values and abilities of the professor.

Such findings are suggestive of the need for faculty training and university faculty development centers. A designated university-wide faculty development center with a learner-centered philosophy is essential to the success of any technology-based distance education program (Bakutes, 1998). Additionally, issues such as tenure, merit, and promotion policies, faculty workload, and the changing roles of professors need to be revisited and revised, as needed, based on the new higher education schoolhouse. Faculty promotion and tenure committees need to adapt promotion and tenure criteria based on the learning paradigm. According to Senge (1990), as cited in Barr and Tagg (1995), changes to the university in support of the learning paradigm are as important as the decision or desire to shift towards the learning paradigm. Consequently, all issues regarding change, to include any moves toward increased use of blended learning, need to be addressed by the school's strategic planning process.

The ability to generalize findings beyond the present study is limited because only three courses at the same university were sampled and the learner characteristics, course content, course design, and pedagogy used by the professors in the present study may not be representative of other professors and other settings. Additionally, the researchers exercised no experimental control over the courses examined in the present study and cause-and-effect relationships were not confirmed.

\section{Conclusion}

The blended concept of learning is highly consistent with the three areas of change identified in the introduction - thinking less about delivering instruction and more about producing learning, reaching out to students through distance education technologies, and promoting a strong sense of community among learners. Indeed, the concept of blended learning may be a synthesis of these areas as the learning environment becomes more learning-centered, with emphasis on active learning through collaboration and social construction of understanding. Such a concept is moving toward O'Banion's (1997) vision of a learning college as a place where learning comes first and educational experiences are provided for learners anyway, anyplace, and anytime. Graham B. Spanier, president of The Pennsylvania State University, referred to this convergence of online and traditional instruction as the single-greatest unrecognized trend in higher education today (Young, 2002). 


\section{References}

Abrahamson, C. E. (1998). Issues in interactive communication in distance education. College Student Journal, 32(1), 33 - 43.

Bakutes, A. P. (1998). An examination of faculty development centers. Contemporary Education, 69(3), $168-171$.

Barr, R. B., and Tagg, J. (1995). From teaching to learning: A new paradigm for undergraduate education. Change, 27(6), $13-25$.

Carr, S. (2000). As distance education comes of age, the challenge is keeping the students. The Chronicle of Higher Education, 46, A39 - A41.

Cohen, J. (1977). Statistical power analysis for the behavioral sciences (revised edition). New York: Academic Press.

Colis, B., and Moonen, J. (2001). Flexible learning in a digital world: Experiences and expectations. London: Kogan-Page.

Collins, M. (1999). I know my instructional technologies: It's these learners that perplex me! The American Journal of Distance Education, 13(1), 8 - 23.

Davis, S., and Botkin, D. (1994). Monsters under the bed. New York: Touchstone.

Dziuban, C., and Moskal, P. (2001). Evaluating distributed learning in metropolitan universities. Metropolitan Universities, 12(1), $41-49$.

Gardiner, L. (1994). Redesigning higher education: Producing dramatic gains in student learning. ASHE-ERIC Higher Education Report 7. Washington, DC.: George Washington University.

Gardiner, L. (1998). Why We Must Change: The research evidence. Thought and Action, 14(1), $71-88$.

Hara, N., and Kling, R. (2001). Student distress in web-based distance education. Educause Quarterly, 3, $68-69$.

Haythornthwaite, C., Kazmer, M., Robins, J., and Shoemaker, S. (2000). Making Connections: Community among computer-supported distance learners. Paper presented at the Association for Library and Information Science Education 2000 Conference. San Antonio, Texas. Retrieved July 3, 2003 from: http://www.alise.org/conferences/conf00 Haythornthwaite Making.htm

Irizarry, R. (2002). Self-efficacy and motivation effects on online psychology student retention. USDLA Journal, 16(12), 55 - 64.

Marino, T. A. (2000). Learning Online: A view from both sides. The National Teaching \& Learning Forum, 9(4), 4 - 6. 
Martyn, M. (2003). The Hybrid Online Model: Good practice. Educause Quarterly, 1, 18 - 23.

McCarthy, M. E., Pretty, G. M. H., and Catano, V. (1990, May). Psychological sense of community and student burnout. Journal of College Student Development, 31, $211-216$.

McMillan, D. W., and Chavis, D. M. (1986). Sense of Community: A definition and theory. Journal of Community Psychology, 14(1), 6 - 23.

Morgan, C. K., and Tam, M. (1999). Unraveling the complexities of distance education student attrition. Distance Education, 20(1), 96 - 108.

Neff, J. (1998). From a Distance: Teaching writing on interactive television. Research in the Teaching of Writing, 33(2), 136-157.

O’Banion, T. (1997). A learning college for the 21st century. Phoenix, AZ.: Oryx Press.

Privateer, P. M. (1999). Academic technology and the future of higher education: Strategic paths taken and not taken. The Journal of Higher Education, 70(1), 60 - 79.

Rovai, A. P. (2002). Development of an instrument to measure classroom community. Internet and Higher Education, 5(3), 197 - 211.

Rury, J. (1996). Inquiry in the general education curriculum. Journal of General Education, 45(3), $175-196$.

Senge, P. (1990). The Fifth Discipline: The art and practice of the learning organization. New York: Doubleday Currency.

Sergiovanni, T. J. (1994). Building community in schools. San Francisco: Jossey-Bass.

Sikora, A. C., and Carroll, C. D. (2002). Postsecondary education descriptive analysis reports (NCES 2003-154). US Department of Education, National Center for Education Statistics. Washington, DC.: US Government Printing Office.

Tinto, V. (1975). Dropout from Higher Education: A theoretical synthesis of recent research. Review of Educational Research, 45(1), 89- 125.

Voos, R. (2003). Blended Learning: What is it and where might it take us? Sloan-C View 2(1), 2 5.

Young, J. R. (2002, March 22). Hybrid teaching seeks to end the divide between traditional and online instruction. The Chronicle of Higher Education, A33.

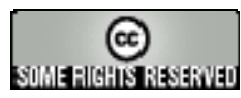

